\title{
Source adoption in Northern Victoria: a hydrological model of an integrated Goulburn, Broken, Campaspe, Coliban and Loddon Rivers system
}

\author{
$\underline{\text { Yong Li }}{ }^{\text {a }}$, Uttam Manandhar ${ }^{\text {a }}$ and Seker Mariyapillai ${ }^{\mathrm{a}}$ \\ a Department of Environment, Land, Water and Planning, Victoria \\ Email: yong.li@delwp.vic.gov.au
}

\begin{abstract}
Surface water models are fundamental in providing the evidence to inform policy and investment decision making to sustainably manage water resource planning and operations. The Victorian Department of Environment, Land, Water and Planning (DELWP) is committed to ensuring that future water planning and management are informed by using best practice modelling. eWater Source, a key deliverable of the Australian National Hydrological Modelling Strategy, is designed to simulate aspects of water resource systems in a consistent, transparent and defensible manner. The development of a daily timestep Source model for the Northern Victorian catchment of the Goulburn, Broken, Campaspe, Coliban and Loddon (GBCCL) Rivers has been one of the key elements of Victoria's transition to the eWater Source software platform.
\end{abstract}

The GBCCL catchment has the most complex operating and water sharing arrangements in Victoria to meet the consumptive and environmental demands of rural and urban water supply systems. A daily timestep Source GBCCL foundational model has now been successfully configured to simulate the water supply system of the Goulburn, Broken, Campaspe, Coliban and Loddon Rivers including the Waranga Western Channel and East Goulburn Main Channel systems. The model has been developed using daily data inputs that cover more than 120 years over the period from January 1891 to June 2014 and generally represents a level of development based on conditions in 2009 with the most up-to-date information. The model simulates multiple sources of water supply under various water management and operating rules, bidirectional flows, storage capacity sharing between water corporations, urban restrictions, annual accounting resource assessments for five subsystems and carryover rules.

Adopting commonly used graphical techniques for overview of a model performance, the Source GBCCL model results are compared with historical records using time series, exceedance and cumulative plots for the period from 1994 to 2009. Given the model generally represents a level of development based on conditions in 2009, differences are expected when compared with historical records. Despite some differences, the comparison of storage volumes, flows and seasonal determinations between the modelled and the observed generally shows a good agreement.

Similarly, the Source model results also compare with the results from the existing model of the system, the monthly timestep Goulburn Simulation Model (GSM) developed using the REsource ALlocation Model (REALM) software. They are also generally close for all sub-systems although some differences exist, which will be further investigated and explained. Furthermore, there are some recommended improvements to be made to the Source GBCCL model in the future.

The foundational version of the daily Source GBCCL model is currently configured as a planning model with complex annual accounting resource assessment systems. With further improvements, it can be utilised for compliance purposes as well as a tool for assessment of policy and management options, and the possible impacts of options on the water supply systems. If a need exists, the model could be modified and extended to be an operational tool in the future.

The successful implementation of Source for the integrated GBCCL system, a key pillar of Victoria's transition to the Source modelling platform, demonstrates that Source can be a 'fit-for-purpose' modelling platform to replace the existing REALM software. This has also provided confidence for transition from the REALM to Source modelling platform in Victoria.

Keywords: Source adoption, hydrological modelling, water resource management 
Li et al., Source adoption in Northern Victoria: a hydrological model of the integrated Goulburn, Broken, Campaspe, Coliban and Loddon Rivers system

\section{INTRODUCTION}

Surface water models are fundamental in providing the evidence to inform policy and investment decision making to sustainably manage water resource planning and operations. Victoria has been supporting the Council of Australian Governments endorsed National Hydrological Modelling Strategy since its initiation through funding and technical inputs to the development of the Source Integrated Modelling System (Source). The Victorian Department of Environment, Land, Water and Planning (DELWP) is committed to ensuring that future water planning and management are informed by using best practice modelling and has implemented Source in the integrated Goulburn, Broken, Campaspe, Coliban and Loddon (GBCCL) catchment by developing a daily timestep Source model, which is referred to as the Source GBCCL model in this paper.

The Source implementation catchment is Northern Victoria, covering an approximate area of 38,900 sq. $\mathrm{km}$. The extent of the model is shown by the green boundary in Figure 1. The catchment, comprising of five sub-catchments - Goulburn, Broken, Campaspe, Coliban and Loddon - has the most complex operating and water sharing arrangements in Victoria to meet consumptive and environmental demands of rural and urban water supply systems.

The Source GBCCL model has been developed using daily data inputs that cover more than 120 years over the

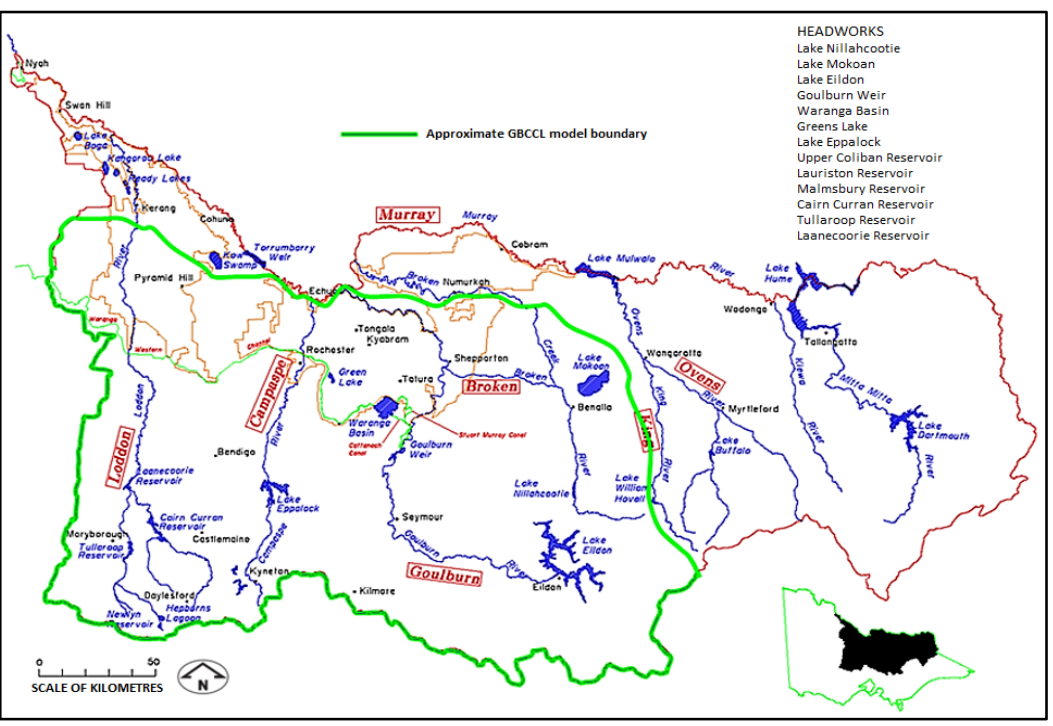

Figure 1. Goulburn-Broken-Campaspe-Coliban-Loddon implementation catchment period from January 1891 to

June 2014 and best available up-to-date system information. The model is configured as a foundational model to generally represent the conditions as in 2009 with a wide range of water authorities' water management and operating rules. It simulates multiple sources of water supply under various water management and operating rules, bidirectional flows, storage capacity sharing between water corporations, urban restrictions, annual accounting resource assessments for five sub-systems and carryover rules.

This paper describes an overview of the daily Source model for the integrated GBCCL water supply system and is not intended to include detail on the methods of modelling different aspects of the water system. Results from the Source GBCCL model are compared with the historical records and the results from the existing model of the system, the monthly timestep Goulburn Simulation Model (GSM) developed using the REsource ALlocation Model (REALM) software.

\section{BACKGROUND}

\subsection{Physical system}

Each water supply system in the GBCCL catchment comprises its own network of storages, rivers, creeks and channels, to store and distribute water to downstream users. The Goulburn River is a major tributary of the Murray system. Lake Eildon is the main storage in the Goulburn sub-system, which harvests and stores water for use. Waranga Basin is an off-stream storage that can harvest water from the tributaries downstream of Lake Eildon. The Broken River, a major tributary of the Goulburn River, includes Lake Nillahcootie and Casey's Weir, and supplies to private diverters and the Broken Creek system. Lake Mokoan in the Broken sub-system was decommissioned in December 2009 for water savings and the site was restored as the Winton Wetland complex. Cairn Curran Reservoir and Tullaroop Reservoir are the major storages in the Loddon sub-system. Laanecoorie Reservoir is a smaller storage on the Loddon River downstream of both Cairn Curran and Tullaroop Reservoirs. The Coliban sub-system, comprising of a number of storages, rivers, creeks and channels within the Campaspe catchment, stores and distributes water to Coliban Water (CW) customers for urban and 
Li et al., Source adoption in Northern Victoria: a hydrological model of the integrated Goulburn, Broken, Campaspe, Coliban and Loddon Rivers system

rural use. Coliban Water manages this sub-system, including an inflow and a storage share in Lake Eppalock in the Campaspe River. The Campaspe sub-system is managed by Goulburn-Murray Water (GMW) and includes the major storage, Lake Eppalock.

The primary purpose of storages in the integrated water supply system is to hold water and supply to water entitlement holders for the purpose of irrigation, domestic and stock, urban use and environmental water requirements. Water for irrigation is delivered via the river and channel systems to four large gravity irrigation areas that extend from Shepparton in the east to Boort in the west. Additionally, water from the Campaspe and Loddon sub-systems can be used to meet irrigation demand within the Goulburn sub-system via supplements from the Campaspe and Loddon Rivers when water is available.

\subsection{Historical modelling approach}

The existing water resources model of the GBCCL river basins is the Goulburn Simulation Model (GSM). The model was built in the REALM software in 1990/91 using Network Linear Programming (NetLP). Since that time, the model has been progressively developed to represent current development conditions, including simulation of the major storages, water supply infrastructure, operating and management policies, distribution system losses and environmental demands. The GSM has been used for more than twenty-five years to support the development and implementation of major water policy initiatives such as the development of bulk entitlements, the implementation of the Murray Darling Basin Cap, water savings projects and the MurrayDarling Basin Plan.

The key limitation of the GSM is the monthly timestep simulation. The GSM timestep limits the ability to simulate environmental demands and deliveries, which are often specified on a daily basis. The daily timestep simulation has progressively become more important because environmental flow requirements and water holdings have increased substantially over the last decade.

\subsection{Source trial application}

During the Source software development, four trial application catchments in the Murray-Darling Basin (MDB), namely Goulburn-Broken-Campaspe-Loddon (GBCL), Macintyre Brook, Namoi and Murray, were chosen to cover river systems with different physical and hydrological characteristics and management aspects across the jurisdictions. The desired outcome from the trial applications is the confidence that Source will be a 'fit-for-purpose' modelling platform to replace the existing modelling platforms used in MDB. The outcome of Victorian GBCL trial application in 2012 was a version of monthly timestep Source model of the catchment, using the NetLP ordering algorithm and functionality that were available then in Source (Li et al. 2012).

Since the new rules-based ordering algorithm became available in Source, the purpose of the development of the Source GBCCL model has been to assess Source as a 'fit-for-purpose' modelling platform on a daily timestep in the Victorian context. The model should represent the physical, regulatory and management rules of the integrated Goulburn, Broken, Campaspe, Coliban and Loddon Rivers system, which can be used for a wide range of applications including:

- Long term water resource planning for these river basins in the Murray-Darling Basin;

- Simulation of current and proposed water policy initiatives;

- Simulation of physical system changes such as new infrastructure, water savings works, trading of entitlements, changing irrigation demand requirements;

- Assessment and planning of environmental flow demands, and deliveries of environmental water holder entitlements;

- Operation of the river systems; and

- Simulation of salinity in each river basin and its tributaries for Basin Salinity Management purposes.

\section{SOURCE MODEL DEVELOPMENT}

\subsection{Model conceptualization}

Figure 2 shows a simplified schematic of the major components of the water grid in the GBCCL catchment, which demonstrates the connection of water resources via a network of natural and built infrastructure to supply various demands (e.g. Goulburn-Murray Irrigation Areas). It contains five sub-systems Goulburn, Broken, Campaspe, Coliban and Loddon, as well as Waranga Western Channel (WWC) and East Goulburn Main Channel (EGM) systems. In Figure 2, Goulburn, and WWC \& EGM sub-systems are labelled as water supply systems 1 and 6 respectively, the other sub-systems being labelled as water supply systems 2 to 5 . 
Li et al., Source adoption in Northern Victoria: a hydrological model of the integrated Goulburn, Broken, Campaspe, Coliban and Loddon Rivers system

It is noted that the demands supplied at the downstream end of the WWC (e.g. Boort Irrigation Area) have multiple sources of supply. While most of the demand is supplied from the Goulburn sub-system, during periods of peak demand the channel capacity constraints often restrict the normal supply and demand is supplemented from the Loddon and Campaspe sub-systems.

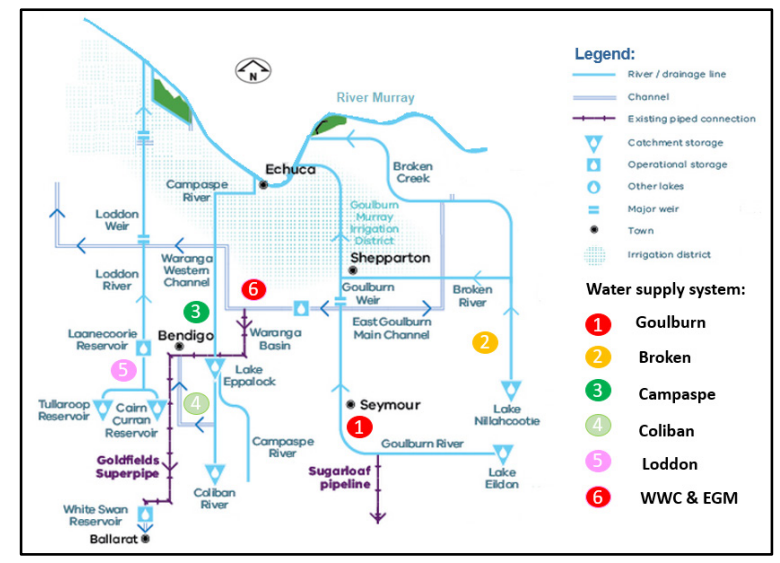

Figure 2. Schematic representation of the GBCCL water grid

\subsection{Model configuration}

As river systems in Source are schematised into a simplified river network using a node-link structure, a set of nodes, links and functionality have been used to model the physical and management processes in this integrated water supply system. Two routing methods including lag flow routing and storage routing are available to model travel time and attenuation along the main river reaches. Generally, piecewise storage routing is used in links for routing in the Source GBCCL model.

The hydrological conceptualisation and configuration of the daily timestep Source GBCCL model was initially built based on the GSM. However, significant work has been undertaken to improve and refine the hydrological configuration of the Source GBCCL model to better represent the water grid and the conditions of the water supply system in 2009. For instance, the Goldfields Superpipe in the Coliban sub-system has been configured in the model, and it can operate in both directions between Lake Eppalock and Bendigo. Furthermore, inflows and diversions in the Source GBCCL model have smaller spatial coverages, as the sub-catchments represented in the Source GBCCL model are generally smaller than those represented in the GSM. Figure 3 below shows the system schematic of the daily Source GBCCL model.

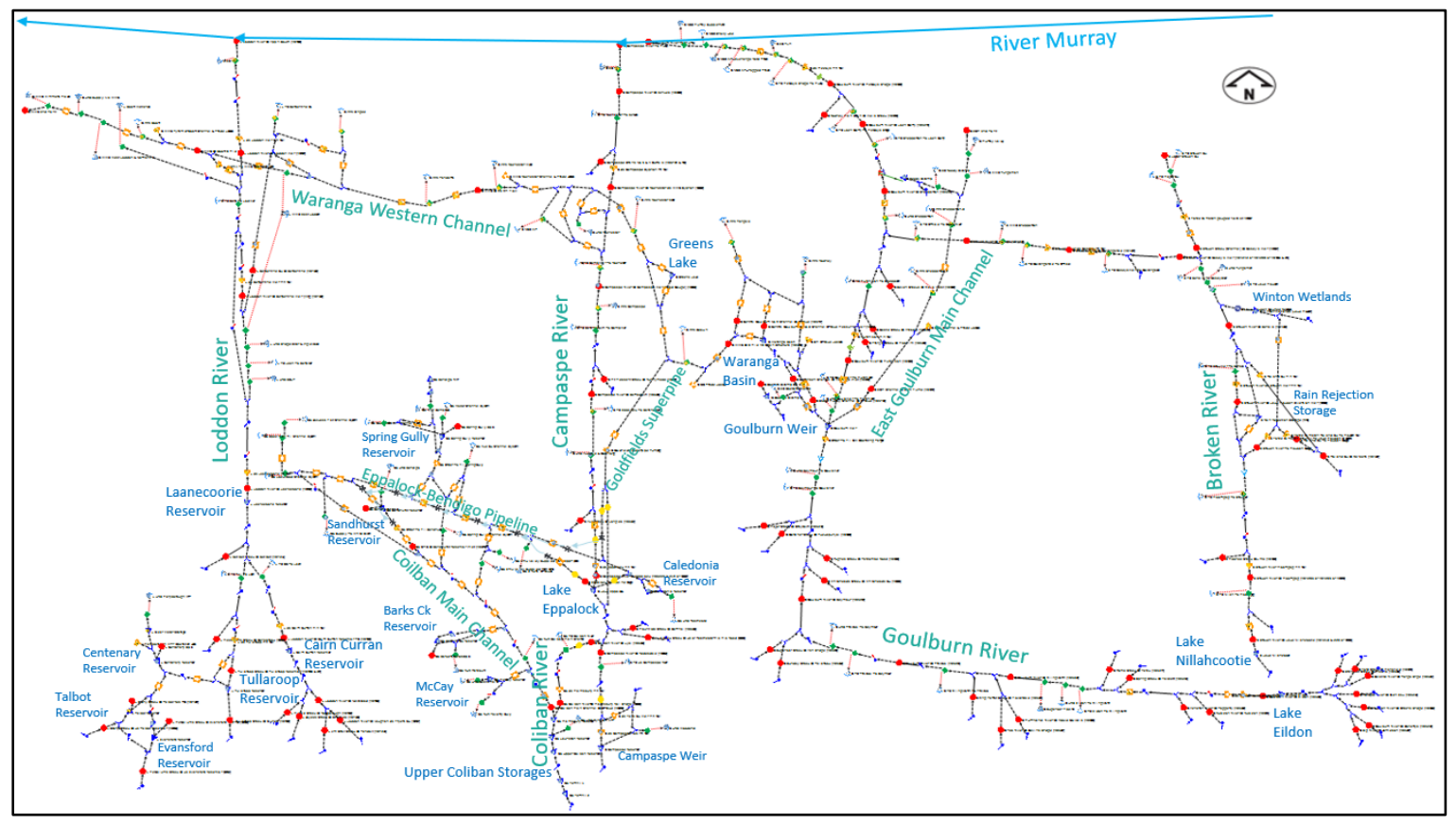

Figure 3. Schematic of the daily timestep Source GBCCL model 
Li et al., Source adoption in Northern Victoria: a hydrological model of the integrated Goulburn, Broken, Campaspe, Coliban and Loddon Rivers system

The key management and operating rules simulated in the Source GBCCL model for the 2009 conditions include:

- All major storages, releases from reservoirs/weirs and relevant storage operating rules;

- Flow routing and representative order times throughout the river systems;

- River losses in the Goulburn, Broken, Campaspe, Coliban and Loddon Rivers;

- Passing flow rules along the Goulburn, Broken, Coliban, Campaspe and Loddon Rivers;

- Operational and physical constraints in river/channel systems, and flooding constraints in the rivers;

- Multiple sources of supply and passing of orders to the upstream storages based on harmony rules;

- Supply to Goulburn Irrigation Areas via EGM and WWC, Campaspe Irrigation District, private diverters and urban centres;

- Operation of bidirectional flow in the Eppalock-Sandhurst pipeline;

- Loddon and Campaspe supplements to the Goulburn sub-system;

- Other supplementary supplies, namely Goulburn supplements to Murray and Broken Creek systems;

- Annual resource assessments for Goulburn, Broken, Coliban, Campaspe and Loddon irrigation supply;

- Various water accounting arrangements for water users including Inter Valley Trade (IVT), The Living Murray (TLM), Snowy use and other accounts;

- Urban restrictions based on volume in storages and/or inflows;

- Storage capacity and inflows sharing between water corporations at Lake Eppalock; and

- Prioritisation of demand shortfalls between different water users.

Application of the rules for sharing the water between the water corporations has been implemented using the Source ownership functionality. Four ownership systems are set up in the model to track and manage each water corporation's share at each model component in the relevant ownership system.

In Victoria, Bulk Entitlements (BEs) have been issued to water authorities to clearly define their respective rights to water (NRE, 1995). The BEs define different types of water shares, volumetric entitlements or licensed volumes of the water shares owned by different users, resource assessment issues, passing flow requirements and other information specific to each supply system. Seasonal determinations (SDs) are the means for sharing available water between individual entitlement holders each year and generally announced as a percentage of the annual volumetric entitlements of the water users in a seasonal determination group (e.g. a sub-system in the GBCCL catchment). Five annual accounting resource assessments have been implemented for Goulburn, Broken, Campaspe, Loddon and Coliban sub-systems for announcing seasonal determinations from 1 July (first SD of a season) until 1 April (last SD of a season) during a water year. Resource assessments are undertaken fortnightly on the first and 15th day of each month using annual accounting of available resources together with carryover and spill rules. The methods applied for the assessments in the Goulburn, Broken, Campaspe and Loddon sub-systems are based on the rules specified in the relevant BEs for SDs and Goulburn-Murray Water seasonal determination policies that apply in these systems.

Ordering priority functionality in Source allows users to specify how shortfalls are prioritised between different demands in a regulated river system due to physical constraints and/or insufficient water available in the supply system. In general, the demand ordering priorities in the Source GBCCL model are specified in the following order: 1) Minimum flow requirements/passing flows; 2) Weir operating targets and urban demands; 3) Rural/irrigation demands; 4) Storage operating targets; and 5) Orders for wetlands. The Source ordering system will meet the highest priority demands first and subsequently, the lower priority demands in sequence.

Model calibration has been undertaken on the various components of the model and the model as a whole. The Source GBCCL model has been calibrated on a reach by reach basis for routing, losses and residual inflows using gauged flows at the upstream and downstream ends of each reach. Furthermore, adopting commonly used graphical techniques for overview of a model performance, the model has been assessed by comparing the model results (flows at key locations, supplied demands, volumes in key storages and seasonal determinations) with the historical records and the results from the existing GSM using time series, exceedance curves and cumulative plots. When significant differences are observed, they are explained where possible.

\section{RESULTS AND DISCUSSION}

The daily Source GBCCL model has a scenario generally configured to represent 2009 conditions and run for the period from 1 July 1994 to 30 June 2009 using Source beta version 4.8.3. A comparable scenario of the REALM GSM is a model version that represents conditions as in 2009. The results from the two models, namely simulated flows, storage volumes, seasonal determinations and mass balances have been compared. Given the large number of plots, only the plots for one major storage and one flow site for each sub-system, together with seasonal determinations for the Goulburn and Campaspe sub-systems are presented (Figures 4, 
Li et al., Source adoption in Northern Victoria: a hydrological model of the integrated Goulburn, Broken, Campaspe, Coliban and Loddon Rivers system

$5,6,7,8$ and 9). For the purposes of comparing the monthly GSM outputs with the daily Source outputs, the GSM flow data have been disaggregated using a uniform pattern within each month. The Source model outputs therefore show within month variability whereas the GSM outputs do not.
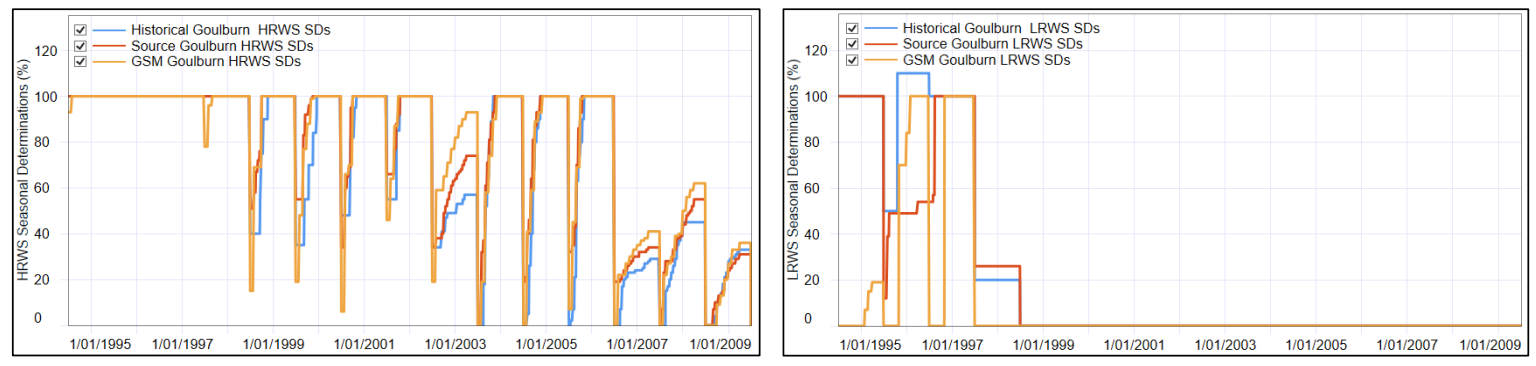

Figure 4. Goulburn HRWS and LRWS seasonal determinations
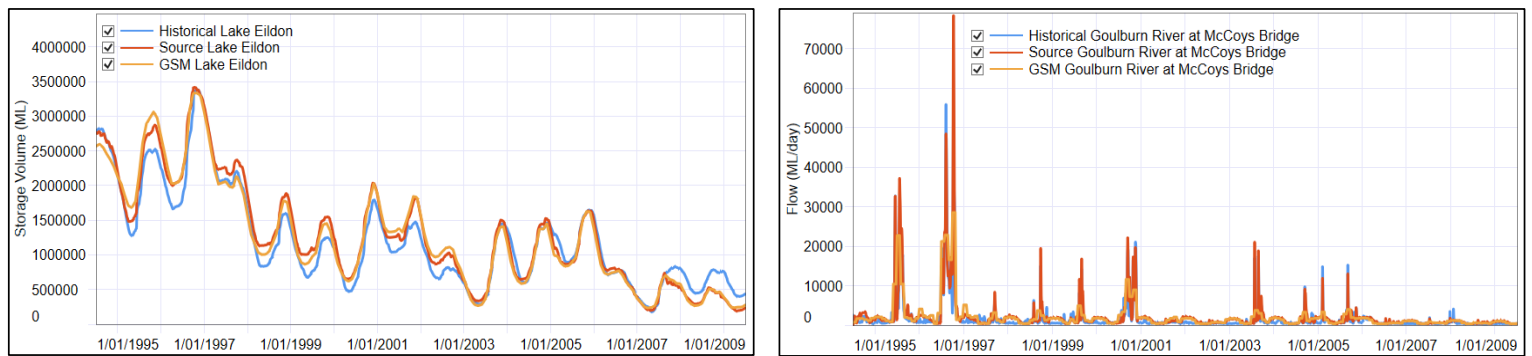

Figure 5. Lake Eildon storage volumes and Goulburn River flows at McCoy’s Bridge (405232)
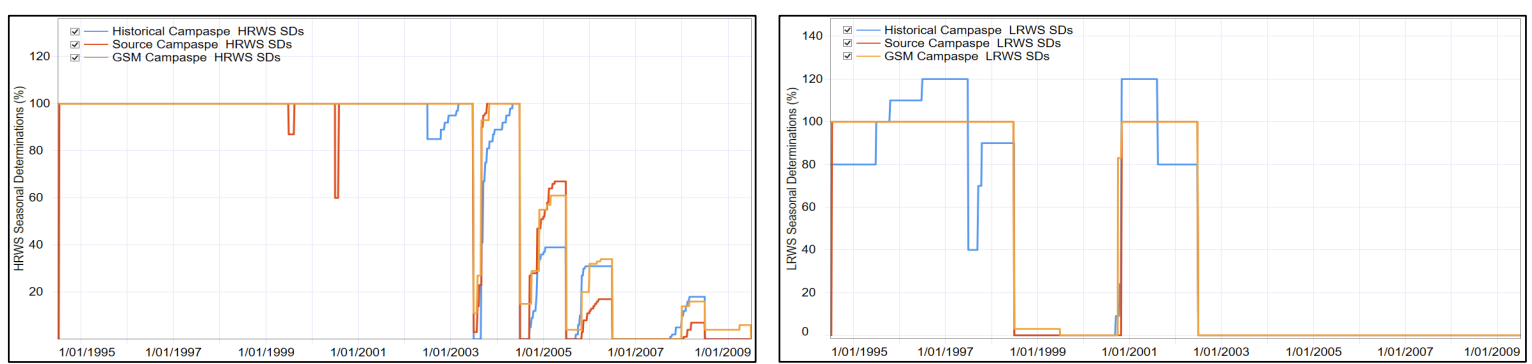

Figure 6. Campaspe HRWS and LRWS seasonal determinations
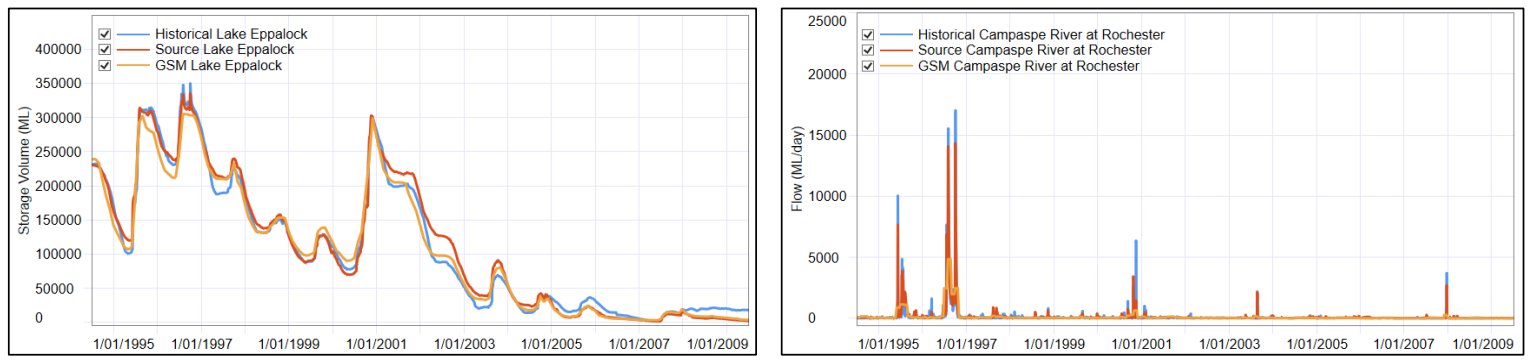

Figure 7. Lake Eppalock storage volumes and Campaspe River flows at Rochester (406202)
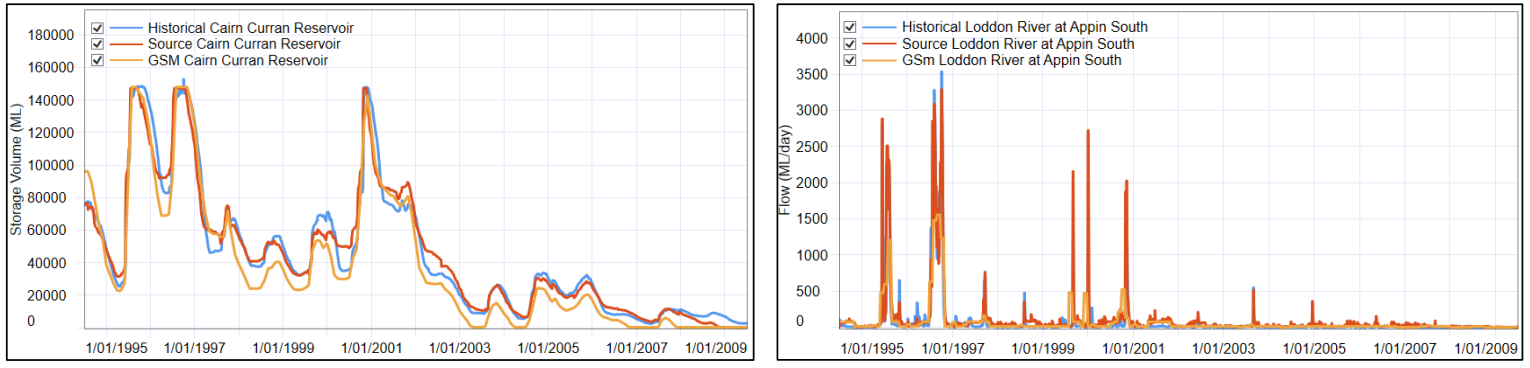

Figure 8. Cairn Curran Reservoir storage volumes and Loddon River flows at Appin South (407205) 
Li et al., Source adoption in Northern Victoria: a hydrological model of the integrated Goulburn, Broken, Campaspe, Coliban and Loddon Rivers system
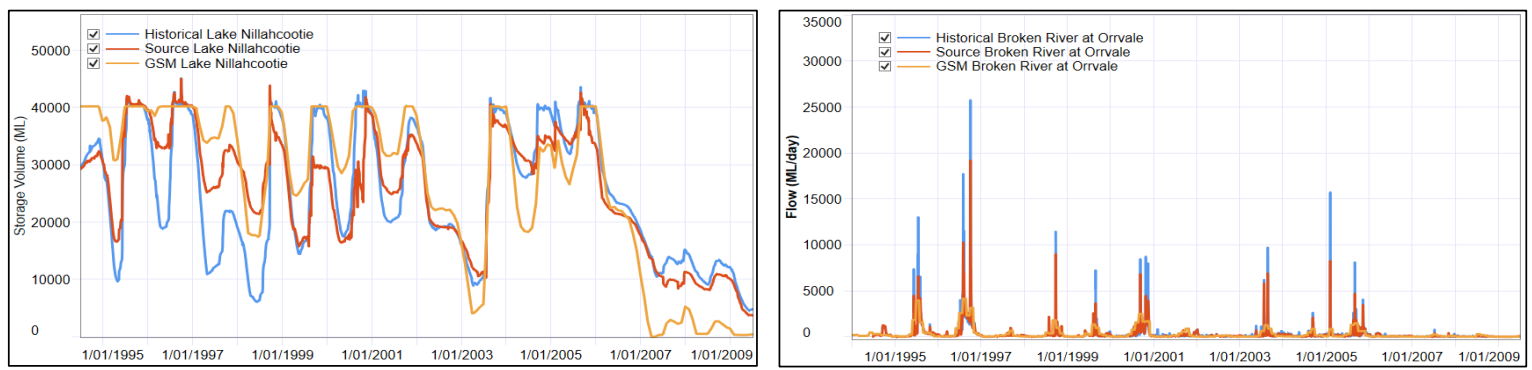

Figure 9. Lake Nillahcootie storage volumes and Broken River flows at Orrvale (404222)

The Source model results are generally close to the GSM for all sub-systems with some differences, which will be further investigated and explained. While the model reproduces the historical storage behaviour reasonably well, with the model slightly underestimating the storage volumes during very dry periods (e.g. 2007 to 2009). The time series plots in Figure 5 for the simulated and historical flows in the Goulburn River at McCoy's Bridge (405232) show that during the drought years the simulated flow often exceeds the historical flow.

Given that the model generally represents a level of development based on conditions in 2009, differences are expected when the model results are compared with historical storage, flow and seasonal determination records. The model generally shows a good agreement with the historical records. Differences between model results and historical records are mainly due to the fact that actual system conditions, system operational and management rules (e.g. storage operating targets, decommissioning of storage and releases of IVT, Snowy water etc.) changed over time and differed from those in the model for the period.

\section{CONCLUSIONS AND RECOMMENDATIONS}

This paper presented an overview of the daily timestep Source foundational model for the integrated Goulburn, Broken, Campaspe, Coliban and Loddon water supply system. The performance of the daily Source GBCCL model generally provides a good agreement with the historical records and is also generally close to the monthly GSM results for all sub-systems. This has demonstrated a major achievement in terms of the longterm objective of moving from a monthly to daily timestep for model development in Northern Victoria. Recommended improvements to the Source GBCCL model include:

- Extension of the model input data to the most recent year;

- Improvement of distribution losses;

- Incorporation of temporary trade;

- Representation of non-consumptive demands; and

- Modelling of irrigation and environmental demands.

The foundational version of the daily Source GBCCL model is currently configured as a planning model with complex annual accounting resource assessment systems. With further improvements, it can be utilised for compliance purposes as well as a tool for assessment of policy and management options, and the possible impacts of options on the water supply systems. If a need exists, the model could be modified and extended to be an operational tool in the future.

The successful implementation of Source for the integrated GBCCL system, a key pillar of Victoria's transition to the Source modelling platform, demonstrates that Source can be a 'fit-for-purpose' modelling platform to replace the existing REALM software. This has also provided confidence for transition from the REALM to Source modelling platform in Victoria.

\section{ACKNOWLEDGMENTS}

The authors gratefully acknowledge the support provided by the eWater Source software development project team to fix bugs and enhance the software as identified and required for this work.

\section{REFERENCES}

NRE (1995). The Bulk Entitlement Conversion Process. Bulk Entitlements Report Series No. 2, Department of Natural Resources and Environment, Victoria.

Li, Y., Manandhar, U. and James, B. (2012). Modelling Goulburn-Broken-Campaspe-Loddon Catchment with "Source Rivers" Software. Paper presented at Hydrology \& Water Resource Symposium 2012, Sydney, Australia, November $19-22$. 